\title{
GPC Temperature Control of A Simulation Model Infant-Incubator and Practice with Arduino Board
}

\author{
E. Feki \\ University of Tunis El Manar, \\ Faculty of Science, \\ UR17ES11 LAPER, 2092 Tunis, \\ Tunisia
}

\author{
M. A. Zermani \\ University of Tunis El Manar, \\ Faculty of Science, \\ UR17ES11 LAPER, 2092 Tunis, \\ Tunisia
}

\author{
A. Mami \\ University of Tunis El Manar, \\ Faculty of Science, \\ UR17ES11 LAPER, 2092 Tunis, \\ Tunisia
}

\begin{abstract}
The thermal environment surrounding preterm neonates in closed incubators is regulated via air temperature control mode. At present, these control modes do not take account of all the thermal parameters involved in a pattern of incubator such as the thermal parameters of preterm neonates (birth weight $<1000$ grams). The objective of this work is to design and validate a generalized predictive control (GPC) that takes into account the closed incubator model as well as the newborn premature model. Then, we implemented this control law on a DRAGER neonatal incubator with and without newborn using microcontroller card. Methods: The design of the predictive control law is based on a prediction model. The developed model allows us to take into account all the thermal exchanges (radioactive, conductive, convective and evaporative) and the various interactions between the environment of the incubator and the premature newborn. Results: The predictive control law and the simulation model developed in Matlab/Simulink environment make it possible to evaluate the quality of the mode of control of the air temperature to which newborn must be raised. The results of the simulation and implementation of the air temperature inside the incubator (with newborn and without newborn) prove the feasibility and effectiveness of the proposed GPC controller compared with a proportional-integral-derivative controller (PID controller).
\end{abstract} GPC

Keywords-Incubator; neonatal; model; temperature; Arduino;

\section{INTRODUCTION}

For many years, incubators have been used to create a comfortable and healthful hygrothermal environment for neonates. Within this context, a neonatal incubator contributes to better newborns [1]. The newborn premature needs favourable conditions to ensure minimum energy expenditure as well as a safe temperature range; therefore the neonatal incubator is considered to be one device which will ensure a thermoneutral environment [2], [3]. In closed type incubators, the internal temperature can be completely controlled. This property decreases the neonate temperature variance due to large differences between the air and the skin temperature.

Most authors have limited their research to a mathematical model [3]-[5] useful for a computer simulation of the neonateincubator system with classical controller (ON-OFF or PID); [6] developed a simulator of neonatal energy transfer to provide a convenient and precise comparison of sensible heat loss in the incubator. [7] describes the fundamental equations involved in the thermal exchange between infants and their environment. [8] has developed a theoretical model of infant incubator dynamic for the analysis of the factors that influence neonatal thermoregulation.

Reference [9] has developed a comprehensive mathematical model of the closed-loop newborn incubation system in a manner that takes into account all the exchange relations. This model is exploited to perform simulations by Matlab/Simulink. The PID controller is used to control the simulation model for each mode; air servo controlled and skin servo controlled.

Other authors have used the mathematical model of the infant-incubator with a more advanced controller (fuzzy logic or predictive) but without taking into account all of the interactions between a premature infant and an incubator. [10] has developed a fuzzy logic control which integrates two inputs (incubator air temperature and infant's skin temperature) to control the heating. The controller is tested on a mathematical simulation model of the neonatal incubator.

Reference [11] presents a theoretical modelling on the thermal behaviour of the premature infant (only the thermal exchanges of the incubator on the infant are considered). Air temperature and humidity, which play a prominent role in convective and evaporative exchanges, are calculated by a coupled transfer function. Additionally, a decoupling of the generalized predictive controller (DGPC) was proposed in order to obtain optimal thermal conditions for immature newborns.

The primary objective of this study is to develop a mathematical model used for a computer simulation that can predict the future temperature calculated continuously and design an appropriate controller to reduce heat loss by evaporation.

For this reason, two models have been developed and described. The first model is a physical model that takes into account all the interactions between the premature infant and the incubator. This model is based on physical and biological equations developed by the work of [8], [9], but modified according to the characteristics of the incubator used in the experiment (Drager 8000C). The main modification is to estimate a new mathematical model of the heating system using system identification method. Therefore the complete infant incubator system is subdivided into six homogeneous compartments: infant's core, infant's skin, incubator's heater, 
incubator's wall, incubator's mattress, and incubator's environmental conditions. A computer simulation for each compartment of the system will be presented and developed using the Matlab/Simulink environment. These Simulink models are then interlocked via internal loops (called interactions), i.e., input and output data fully interlocked.

The second model, based on input-output measurements used in empirical and statistical approaches, will be useful for designing and simulating incubator environment controllers.

The climatic parameters of the neonatal incubator are temperature and humidity, but in this work, we limit ourselves only to the temperature in order to simplify the process. Therefore the incubator process becomes a SISO system (single input, single output). The input is the control signal applied to the heater and the output is air temperature inside the incubator. Its transfer function was identified using recursive identification methods. The validation of the model is performed with the comparison of the results to a series of clinical tests described in the medical literature [12].

Closed incubators that are used in intensive care are usually equipped with a conventional regulation (ON-OFF or PID) [13], [14]. These types of controllers still have little robust capability compared to adaptive controllers. The infantincubator process encounters multiple challenges in the operating environment of the system, such as changing the physical model of the incubator as a result of interactions between the premature infant and its environment and also external disturbances [15], [16] due to the opening of the access door during a medical intervention. In addition, the disadvantage of the PID controller is finding the right parameters, compensating for the system's delay as well as making a stability study. Indeed, an essential question remains: is it possible to ensure an appropriate environment for prematurely born infants using an advanced control strategy, and maintain precisely the output temperature set by the doctor without significant variation over time, regardless of the disturbance?

Therefore, the objective of this study is to answer this question, using predictive control, so it is necessary to have a precise model for the system. The modelling consists in developing a set of equations in order to describe a phenomenon in a reproducible and stimulable way. The nonlinearities that exist in the system and which are represented as parametric uncertainty can be solved using adaptive control. Therefore, we designed and realized a control system based on a microcontroller (Arduino board).

The rest of the paper is organized as: first, the thermodynamic mathematical model of premature infants placed in an infant incubator will be developed; the aim of the proposed model is to develop and study the heat exchange relationships between the infant, its environment and the different compartments of the neonatal incubator. Secondly, applied feedback control systems using GPC control is described in order to control the infant's air temperature. The control of heating element is applied under the constraints of the air temperature and the power of the actuator. In addition, skin temperature and core temperature are monitored because the simulation of the model with MATLAB-Simulink allows us to see these parameters. Finally, an explanation of the incubator process containing the temperature control circuit is used to obtain a simulation and implementation results, and a comparative study between PID and GPC control was carried out in order to show the performance of each strategy.

\section{METHODOLOGY OF MODEL DEVELOPMENT}

In nursing care, the major concern in newborns after birth is to provide them with appropriate thermo-neutral environments, in order to ensure a body temperature within the normal range between $36.5^{\circ} \mathrm{C}$ and $37.5^{\circ} \mathrm{C}$. This can only be realized when newborns are placed in thermoregulation devices, which are also called "infants warmers".

In this section, a spatially lumped mathematical model for an infant incubator will be developed. The laws of conservation of heat and mass will be used in order to obtain the physical model. As a result, the complete infant incubator system will be subdivided into six homogeneous compartments; the neonate core, skin, incubator air space, heater, wall, and mattress (Fig. 1).

Several assumptions were made in the development of the model. Each compartment was assumed to be homogeneous in all properties throughout its substance. All airflow fields in the incubator were assumed to be uniform. The baseline metabolic rate for each size infant was assumed to be that which enabled the infant to maintain his/her own body temperature while in a non-functional incubator.

The conduction of heat from the mattress to the incubator $Q_{\text {mat }}$, was assumed to be negligible. The model developed to describe the rate of change of temperature over time in each of these compartments. The model equations, based upon the law of conservation of energy, were:

$$
\begin{aligned}
& \frac{d T_{c}}{d t}=\frac{Q_{m e t}-Q_{s e n}-Q_{l a t}-Q_{c d}-Q_{b c}}{M_{c} \cdot C_{p c}} \\
& \frac{d T_{s}}{d t}=\frac{Q_{c d}+Q_{b c}-Q_{m c}-Q_{s c v}-Q_{s e}-Q_{s r}}{M_{S} \cdot C_{p s}} \\
& \frac{d T_{a}}{d t}=\frac{Q_{s c v}+Q_{s e}+Q_{h t}+Q_{s e n}+Q_{l a t}-Q_{a c v}-Q_{m a t}}{M_{a} \cdot C_{p a}} \\
& \frac{d T_{w}}{d t}=\frac{Q_{a c v}+Q_{s r}-Q_{c v o}-Q_{r o}}{M_{w} \cdot C_{p w}} \\
& \frac{d T_{m}}{d t}=\frac{Q_{m c}+Q_{m a t}-Q_{i c}}{M_{m} \cdot C_{p m}} \\
& \frac{d T_{\square a}}{d t}=\frac{\theta}{C}
\end{aligned}
$$

The differential operator $\mathrm{D}=\mathrm{d} / \mathrm{dt}$ is used, hence (1) can be written as follows:

$$
T_{c}=\frac{Q_{m e t}-Q_{s e n}-Q_{l a t}-Q_{c d}-Q_{b c}}{M_{c} \cdot C_{p c} \cdot D}
$$

Equation (7) describes the heat flow rate using the heat transfer relationships associated with the infant's body. Each one of the terms of energy rate (in watt) in this equation can be determined as follows. The core of the newborn body produces heat; its expression is:

$$
Q_{m e t}=M_{r s t} \times S_{a}
$$


Concerning the tidal volume and the respiratory rate, we can determine the equations for respiration losses as follows:

$$
Q_{\text {sen }}=I V \times m \times C_{p a} \times \rho_{a} \times\left(T_{e x}-T_{a}\right)
$$

With: $Q_{\text {sen }}$, is the rate of sensible heat energy due to breathing.

$$
Q_{\text {lat }}=I V \times m \times h f g \times \rho_{a} \times\left(\mathcal{W}_{e x}-\mathcal{W}_{a}\right)
$$

With: $Q_{\text {lat }}$, is the latent heat energy by a newborn due to breathing.

In fact, the core loses heat by conduction through the skin layer. Therefore, the rate of conduction heat transfer between core and skin can be written as follows:

$$
Q_{c d}=\frac{\left(T_{c}-T_{s}\right) \times K_{c} \times S_{a}}{\left(m / \rho_{c} \times S_{a}\right)}
$$

All parameters in (11) are defined in the nomenclature. The convective heat lost by the core blood circulation was determined as described in (12):

$$
Q_{b c}=\left(T_{c}-T_{s}\right) \times \rho_{b l} \times b f \times C_{p b} \times V_{c b}
$$

$Q_{b c}$, is the rate of convective heat transfer between core and skin via blood.

We adopt the differential operator D in (2), the infant's skin temperature can be written as:

$$
T_{s}=\frac{Q_{c d}-Q_{b c}-Q_{m c}-Q_{s c v}-Q_{s e}-Q_{s r}}{M_{s} \cdot C_{p s} \cdot D}
$$

Where, $Q_{c d}, Q_{b c}$ are given in (11) and (12), respectively, while the rate of conductive heat loss from the skin in contact with the mattress $Q_{m c}$ can be determined by:

$$
Q_{m c}=A_{s} \times K_{m a t} \times\left(T_{s}-T_{m}\right) / t h_{m}
$$

In addition, the difference in temperature between the skin and the airspace causes convective heat losses in the skin. This can be determined by:

$$
Q_{s c v}=h_{s c v} \times A_{c v} \times\left(T_{s}-T_{a}\right)
$$

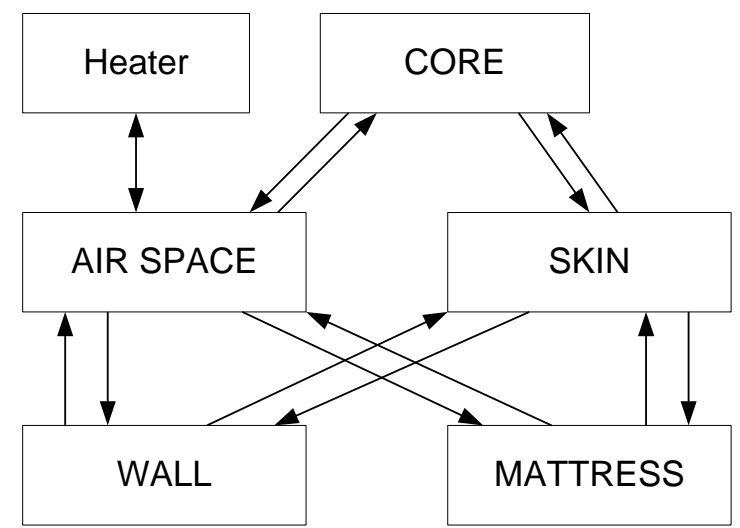

Fig. 1. The neonate-incubator system can be divided into six distinct homogeneous compartments.

The water loss from the skin to the air space through evaporation is inversely proportional to the ambient partial pressure of water vapour. The rate of evaporative heat transfer between skin and incubator air $Q_{s e}$ (in watt) can be determined by:

$$
Q_{s e}=\frac{h f g \times m \times E_{v a p} \times \rho_{h 2 o}}{86400}
$$

The skin also loses heat to the walls of the incubator by radiation. Thus, the rate of radiant heat losses can be determined by:

$$
Q_{s r}=A_{r} \times \sigma \times \varepsilon_{s} \times\left[\left(T_{s}+273.15\right)^{4}-\left(T_{\omega}+273.15\right)^{4}\right]
$$

Using D-operator in (3), the temperature of the air space can be written as:

$$
T_{a}=\frac{Q_{s c v}+Q_{s e}+Q_{\square t}+Q_{s e n}+Q_{l a t}-Q_{a c v}-Q_{m a t}}{M_{a} \cdot C_{p a} \cdot D}
$$

The baby's skin $Q_{s c v}$ allows the airspace of the incubator to gain heat by convection.

Equation (15) is determined by this coefficient and also by the heating compartment $Q_{h t}$ (rate of convective heat energy supplied to the hood).

Concerning the heater modelling, the process is assumed to be adiabatic (i.e., no heat losses) and air absorbed all the heat generated, the temperature of the heated air can be determined as follows:

$$
Q_{\square t}=\dot{m}_{a} C_{p a}\left(T_{\square a}-T_{a}\right)
$$

Where $\dot{m}_{a}$ is the mass flow rate of the incubator air, $\mathrm{kg} / \mathrm{sec}$.

$Q_{s e}$ is a vaporized energy that is caused by water loss from the skin that occurs through evaporation in the airspace. $Q_{s e}$ can be determined using (16).

It should be noted that the air compartment undergoes heat loss by convection through the walls of the incubator, this coefficient $\left(Q_{a c v}\right)$ being defined by the following relationship:

$$
Q_{a c v}=\square_{a c v} A_{w i}\left(T_{a}-T_{w}\right)
$$

Also, the mattress is heated convectively by air. Not the totality of the area of the mattress is the convective heated, therefore, the expression of the area not covered by the infant can be written as follows:

$$
Q_{\text {mat }}=\square_{a c v} A_{\text {net }}\left(T_{a}-T_{m}\right)
$$

With $Q_{\text {mat }}$ is the rate of convective heat transfer between incubator air and mattress.

Using D-operator in (4), the temperature of the wall is determined as follows:

$$
T_{w}=\frac{Q_{a c v}+Q_{s r}-Q_{c v o}-Q_{r o}}{M_{w} \cdot C_{p w} \cdot D}
$$

The convective heat transfer coefficient between the walls of the incubator and the environment is determined as follows:

$$
Q_{c v o}=\square_{c v o} A_{w i}\left(T_{w}-T_{e}\right)
$$

Concerning energy loss from radiation, the heat transfer rate from the walls to the environments can be expressed as follows [17]: 


$$
Q_{r o}=A_{w i} \times \sigma \times \varepsilon_{w} \times\left[\left(T_{w}+273.15\right)^{4}-\left(T_{e}+273.15\right)^{4}\right]
$$

Using D-operator in (5), the mattress temperature $T_{m}$ can be written as:

$$
T_{m}=\frac{\left[Q_{m c}+Q_{m a t}-Q_{i c}\right]}{M_{m} \cdot C_{p m} \cdot D}
$$

Using equations (14) and (21), the energy rate $Q_{m c}$ and $Q_{m a t}$ are then determined, and heat transfer rate from the mattress to the incubator $Q_{i c}$ is assumed to be negligible.

Assume the temperature of the incubator before heat is transferred to be $T_{h a}$. The temperature of the incubator after heat is transferred to be $T_{\text {hai }}$.

Heat transferred to the incubator to be $d q=C d T_{h a}$

$C=$ heat capacity.

By dividing both sides by dt:

$$
\frac{d q}{d t}=\theta=C \frac{d T_{\square a}}{d t}
$$

Equation (26) represents the rate of heat transfer inside the incubator. This rate is governed by a thermal resistance $\mathrm{R}$. This follows a law similar to the law of Ohm:

$$
\theta=\frac{\left(T_{\square a i}-T_{\square a}\right)}{R}
$$

Where, $R$ is the thermal resistance in Kelvin per watt. Using 26 and 27 so we have:

$$
\begin{gathered}
C \frac{d T_{\square a}}{d t}=\frac{\left(T_{\square a i}-T_{\square a}\right)}{R} \\
\frac{d T_{\square a}}{d t}=\frac{\left(T_{\square a i}-T_{\square a}\right)}{C . R}
\end{gathered}
$$

Where the time constant of the system is RC so we have:

$$
\frac{d T_{\curvearrowleft a}}{d t}=\frac{\left(T_{\square a i}-T_{\square a}\right)}{\tau}
$$

Using the Laplace transform "p" we have:

$$
\begin{aligned}
& p . T_{\square a}=\frac{\left(T_{\square a i}-T_{\square a}\right)}{\tau} \\
& T_{\square a}(\tau . p+1)=T_{\square a i} \\
& \frac{T_{\square a}}{T_{\square a i}}(p)=\frac{1}{(\tau . p+1)}
\end{aligned}
$$

The relationship between the applied voltage $(U)$ and the temperature generated by an electrical heater is linear.

$$
T_{\square a i}=K \times U
$$

So we have:

$$
\frac{T_{\square} a}{U}(p)=\frac{K}{(\tau p+1)}
$$

Where $K$ is called the steady state gain and $\tau$ is called the time constant will be defined during the modelling of the heating element in Section V.

\section{IMPLEMENTATION OF PREDICTIVE CONTROL}

In this section, GPC will be well described for a single input-output process based on a CARIMA model.
The standard cost function used in GPC with constraints is expressed by (36).

$$
\begin{aligned}
& J=\sum_{i=N_{1}}^{N_{2}} \delta(i)[\hat{y}(k+i)-w(k+i)]^{2}+\sum_{i=1}^{N_{u}}[\lambda(i) \Delta u(k+ \\
& i-1)]^{2}
\end{aligned}
$$

Where, $N_{1}$ and $N_{2}$ are respectively the minimum and the maximum of the prediction horizon, $N_{u}$ is the control horizon, $\hat{\mathrm{y}}(\mathrm{k}+\mathrm{i})$ is the prediction process output, $w(k+1)$ is the reference signal and $\Delta \mathrm{u}(\mathrm{k}+\mathrm{i}-1)$ is the sequence of the future control increments that have to be calculated. as:

Implicit constraints on $\Delta \mathrm{u}$ are placed between $\mathrm{N}_{\mathrm{u}}$ and $\mathrm{N}_{2}$

$$
\Delta u(k+i-1)=0, \quad N_{u}<i \leq N_{2}
$$

The parameters $\delta(i)$ and $\lambda(i)$ are weighting factors that affect the future behaviour of the controlled process [18]-[20].

\section{A. Calculation of the Optimal Control}

The aim of the predictive control is to calculate a sequence of future control increments $[\Delta u(k), \Delta u(k+1), \ldots]$ so that the criterion (36) is minimized. To facilitate the calculation, it is necessary to transform the criterion (36) to a matrix form.

The form of the output of the prediction model is expressed as the sum of the free response $y_{0}$ and the forced response $y_{n}$.

$$
\hat{y}=y_{n}+y_{0}
$$

The forced response is the multiplication of the Jacobian matrix of the model with the vector of the future control increment.

$$
y_{n}=G \Delta u
$$

Where,

$$
\left[\begin{array}{ccccc}
g_{1} & 0 & 0 & \ldots & 0 \\
g_{2} & g_{1} & 0 & \ldots & 0 \\
g_{3} & g_{2} & g_{1} & \ldots & 0 \\
\vdots & \vdots & \vdots & \ddots & \vdots \\
g_{N_{2}} & g_{N_{2}-1} & g_{N_{2}-2} & \ldots & g_{N_{2}-N_{u}+1}
\end{array}\right]
$$

The elements of this matrix are the values of the steps sequence. by:

Using (38) and (39) the predictor in a vector form is given

$$
\hat{y}=G \Delta u+y_{0}
$$

The cost function (36) can be modified to the form below:

$$
\begin{gathered}
J=(\hat{y}-w)^{T}(\hat{y}-w)+\lambda \Delta u^{T} \Delta u=\left(G \Delta u+y_{0}-\right. \\
w)^{T}\left(G \Delta u+y_{0}-w\right)+\lambda \Delta u^{\mathrm{T}} \Delta u
\end{gathered}
$$

Where, $w$ is the trajectory to follow.

\section{B. Computation of Predictor Second Order System with} Time-Delay as

The nominal model with $d$ steps time-delay is considered

$$
F\left(z^{-1}\right)=\frac{B\left(z^{-1}\right)}{A\left(z^{-1}\right)} z^{-d}=\frac{b_{1} z^{-1}+b_{2} z^{-2}}{1+a_{1} z^{-1}+a_{2} z^{-2}} z^{-d}
$$


The model can be also written in the form

$$
A\left(z^{-1}\right) y(k)=z^{-d} B\left(z^{-1}\right) u(k)
$$

The CARIMA is the most used model in generalized predictive control that can be obtained from a nominal model given by the (43) by adding a disturbance model.

$$
A\left(z^{-1}\right) y(k)=z^{-d} B\left(z^{-1}\right) u(k)+\frac{c\left(z^{-1}\right)}{\Delta} n_{c}(k)
$$

Where, $d$ is the dead time and $n_{c}(k)$ is a non-measurable random disturbance that is assumed to have zero mean value and constant covariance and the operator delta is $1-z^{-1}$. Inverted delta is then an integrator.

The polynomial $C\left(z^{-1}\right)$ will be further considered as $C\left(z^{-1}\right)=1$.

To compute the control action, we must determine the predictions of $d+1$ to $d+N_{2}$. The output at time $(k+t)$ will be:

$$
y(k+t)=\frac{B\left(z^{-1}\right)}{A\left(z^{-1}\right)} u(k+t-d-1)+\frac{C\left(z^{-1}\right)}{A\left(z^{-1}\right) \Delta\left(z^{-1}\right)} n_{c}(k+t)
$$

The Euclidean algorithm applied to the second term of (40) gives the following equation:

$$
\frac{C\left(z^{-1}\right)}{A\left(z^{-1}\right) \Delta\left(z^{-1}\right)}=L\left(z^{-1}\right)+z^{-1} \frac{H\left(z^{-1}\right)}{A\left(z^{-1}\right) \Delta\left(z^{-1}\right)}
$$

Using (40) and (41) we assume that the term related to the disturbance is zero, the optimal predictor of the output is written as follows:

$$
\begin{aligned}
& \quad \hat{y}(k+t)=\frac{L_{t}\left(z^{-1}\right) B\left(z^{-1}\right) \Delta\left(z^{-1}\right)}{C\left(z^{-1}\right)} u(k+t-d-1)+ \\
& \frac{H\left(z^{-1}\right)}{C\left(z^{-1}\right)} y(k)
\end{aligned}
$$

A second Diophantine equation decomposes the predictor in two terms: a first term based on the current output, old orders, the system output and a second term dependent on future orders.

$$
\frac{\sigma\left(z^{-1}\right)}{C\left(z^{-1}\right)}=G_{t}\left(z^{-1}\right)+z^{-1+d} \cdot \frac{R_{t}\left(z^{-1}\right)}{C\left(z^{-1}\right)}
$$

With:

$\sigma\left(z^{-1}\right)=L_{t}\left(z^{-1}\right) B\left(z^{-1}\right)$

The optimal predictor of the output is written as follows:

$$
\begin{aligned}
& \hat{y}(k+t)=G_{t}\left(z^{-1}\right) \Delta\left(z^{-1}\right) u(k+t-d-1)+\frac{H\left(z^{-1}\right)}{C\left(z^{-1}\right)} y(k)+ \\
& \frac{R_{t}\left(z^{-1}\right)}{C\left(z^{-1}\right)} \Delta\left(z^{-1}\right) u(k-1)
\end{aligned}
$$

Where: $G_{t}\left(z^{-1}\right), H\left(z^{-1}\right), R_{t}\left(z^{-1}\right)$, and $L_{t}\left(z^{-1}\right)$ are polynomial solutions to the Diophantine equations.

The matrix formulation is represented as follows:

$$
\hat{y}(k)=\hat{G} \Delta u(k)+\frac{\widehat{H}}{C\left(z^{-1}\right)} y(k)+\frac{\hat{R}}{C\left(z^{-1}\right)} \Delta u(k-1)
$$

With:

$$
\begin{aligned}
& y_{n}=\hat{G} \Delta u(k) \\
& y_{0}=\frac{\widehat{H}}{C\left(z^{-1}\right)} y(k)+\frac{\hat{R}}{C\left(z^{-1}\right)} \Delta u(k-1)
\end{aligned}
$$

The cost function (36) can be modified to the form below:

$$
\begin{gathered}
J=(\hat{y}-w)^{T} \delta(\hat{y}-w)+\lambda \Delta u^{T} \Delta u=\left(G \Delta u+y_{0}-\right. \\
w)^{T} \delta\left(G \Delta u+y_{0}-w\right)+\lambda \Delta u^{T} \Delta u
\end{gathered}
$$

\section{Constrained formulation}

The amplitude of the control signal $u(k)$ is an important object for imposing constraint; we can be expressed by means of the following inequality:

$u_{\min } \leq u \leq u_{\max }$

Where, $u_{\min }$ and $u_{\max }$ are respectively the lower threshold and the upper threshold of the control.

The restrictions on the increase of the control signal take a very simple form and can be expressed by means of the inequality:

$-\Delta u_{\min } \leq \Delta u \leq \Delta u_{\max }$

Where, $\Delta u_{\min }$ and $\Delta u_{\max }$ represent the lower and upper derivative threshold of the control inputs.

On the horizon controller $N_{u}$, can be written:

$$
\begin{aligned}
& -\Delta u_{\min } \leq \Delta u(k) \leq \Delta u_{\max } \\
& -\Delta u_{\min } \leq \Delta u(k+1) \leq \Delta u_{\max } \\
& \vdots \\
& -\Delta u_{\min } \leq \Delta u\left(k+N_{u}-1\right) \leq \Delta u_{\max } \\
& \text { Or in the condensed form: }
\end{aligned}
$$

$$
\left[\begin{array}{c}
I \\
-I
\end{array}\right] \Delta u \leq\left[\begin{array}{c}
b \\
-c
\end{array}\right]
$$

With, I is identity matrix of dimension $\left(N_{u} \times N_{u}\right)$, and

$$
\begin{aligned}
& b=\left[\begin{array}{lll}
\Delta u_{\max } & \cdots & \Delta u_{\max }
\end{array}\right]^{T} \\
& c=\left[\begin{array}{lll}
\Delta u_{\min } & \cdots & \Delta u_{\text {min }}
\end{array}\right]^{T} \\
& \Delta u=\left[\Delta u(k) \cdots \Delta u\left(k+N_{u}-1\right)\right]^{T}
\end{aligned}
$$

The vector of horizon control can be written according to the control constraints:

$$
\begin{gathered}
u_{\min }-u(k-1) \leq \Delta u(k) \leq u_{\max }-u(k-1) \\
u_{\min }-u(k-1) \leq \Delta u(k)+\Delta u(k+1) \leq u_{\max }-u(k-1) \\
\vdots \\
u_{\min }-u(k-1) \leq \Delta u(k)+\cdots+\Delta u\left(k+N_{u}-1\right) \\
\leq u_{\max }-u(k-1)
\end{gathered}
$$

Or in the condensed form:

$$
\left[\begin{array}{c}
T \\
-T
\end{array}\right] \Delta u \geq\left[\begin{array}{l}
-p \\
-h
\end{array}\right]
$$
$\left.N_{u}\right)$.

Where, $\mathrm{T}$ is a lower triangular matrix, dimension $\left(N_{u} \times\right.$

$$
\begin{aligned}
& \text { And } p=\left[\left[u_{\min }-u(k-1)\right] \cdots\left[u_{\min }-u(k-1)\right]\right]^{T}(65) \\
& \text { And } h=\left[\left[u_{\max }-u(k-1)\right] \cdots\left[u_{\max }-u(k-1)\right]\right]^{T}(66) \\
& \text { And } \Delta u=\left[\Delta u(k) \cdots \Delta u\left(k+N_{u}-1\right)\right]^{T}
\end{aligned}
$$

We can rewrite the two inequalities (59) and (64):

$$
\left[\begin{array}{c}
I \\
-I \\
T \\
-T
\end{array}\right] \Delta u \leq\left[\begin{array}{c}
-b \\
-c \\
p \\
-h
\end{array}\right]
$$


$\hat{y}=G \Delta u+y_{0}$

The problem of minimization of the criterion $\mathbf{J}$ with constraints is writing:

$$
\begin{aligned}
& J=\frac{1}{2} \Delta u^{T} Q_{2} \Delta u+Q_{1}^{T} \Delta u+Q_{0} \\
& \text { With : } \\
& Q_{2}=2 G^{T} G+\lambda I \\
& Q_{1}^{T}=2\left(y_{0}-w\right)^{T} G \\
& Q_{0}=\left(y_{0}-w\right)^{T}\left(y_{0}-w\right)=\text { const }
\end{aligned}
$$

The synthesis of the control law GPC consists in minimizing the criterion $J$. The latter cannot be performed by the analytical methods. To solve the problem of optimization of a quadratic criterion under constraints, we used the "fmincon" function of MATLAB.

\section{INCUBATOR PROCESS DESCRIPTION}

In order to research issues related to incubators temperature and to test the results discussed in this paper, a neonatal incubator DRAGER 8000C from Maternal and Neonatal Unit of Rabta-Tunisia is described.

The main points related to such equipment are mentioned in this section. The pilot plant has these parts: a transparent cabinet $(41.2 \mathrm{~cm}$ height, $80.6 \mathrm{~cm}$ length and $44 \mathrm{~cm}$ width); a heater (400Watt), a fan is on all the time. The heater is modified to allow external control with a dimmer (infinitely variable control).

All infant incubators work on the same principle. A fan blows filtered ambient air over a heating element and a water container [21], but in our case, the water container of the incubator was emptied in order to control only the temperature.

The hardware realization of the temperature control circuit is proposed. Fig. 2 illustrates the diagram of the designed electrical circuits. The design consists mainly of a temperature sensor, an Arduino Uno board and a heating power module (dimmer with zero detectors). These parts are explained in more detail in the following paragraphs.

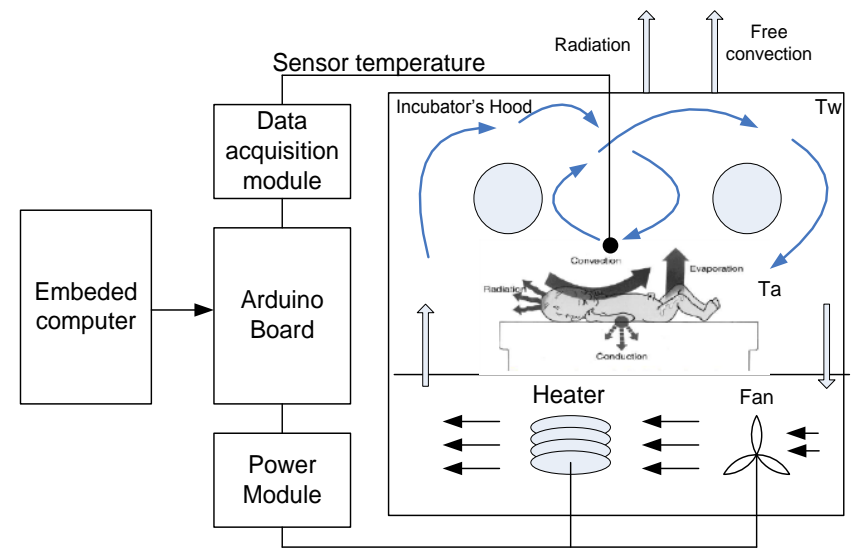

Fig. 2. Schematic of the incubator process with experimental arrangement.

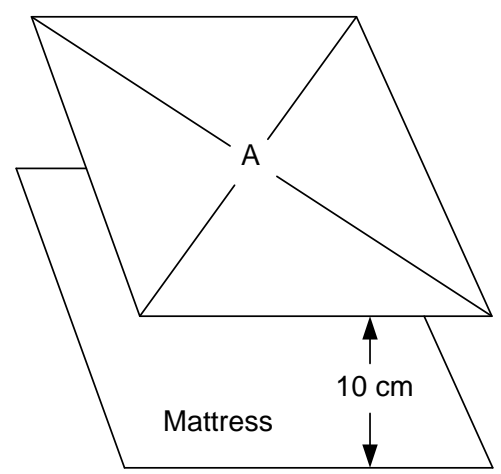

Fig. 3. Location of the point of measurement of the mattress in accordance with the standard NBR-IEC 601-2-19.

\section{A. Temperature Sensing}

The LM35DZ is a temperature sensor that delivers an output voltage linearly proportional to the Celsius temperature $\left(+10 \mathrm{mV} /{ }^{\circ} \mathrm{C}\right)$. This sensor is selected because no further external calibration is required; its accuracy is $\pm 1 / 4{ }^{\circ} \mathrm{C}$. It operates at 4-30 V. In this experiment, the LM35DZ was connected to a $5 \mathrm{~V}$ DC power supply. The temperature was considered an important parameter in neonatal incubators. This parameter was measured at point $A$, located $10 \mathrm{~cm}$ above the surface of the mattress with the same low horizontal position, as shown in Fig. 3 [22].

\section{B. Arduino Board}

The Arduino Uno is a microcontroller card based on the ATmega328. This card has $14 \mathrm{I} / \mathrm{O}$ pins (6 pins of which can be used as PWM outputs), 6 analogue input pins, $16 \mathrm{MHz}$ ceramic resonator, USB connection, power socket, ICSP header and reset button [23], [24].

The Arduino board is selected to design the heat control circuit; it is able to acquire the temperature by means of the analogue input (for example the temperature inside the incubator Ta), also to vary the power of the control devices through a dimmer (for example the power of the heating system) in order to accomplish some real operations (e.g., temperature control of an incubator). The data acquisition module uses analogue inputs that operate at a 10-bit resolution, which provides a scale from 0 to 1023 .

The ready structure of the Arduino is the most advantageous compared to the other card. This card is delivered in a complete package including a microcontroller, a $5 \mathrm{~V}$ regulator, an oscillator, a serial communication interface and headers for connections. In addition, Arduino is easily connected to Matlab/Simulink which is a powerful tool to identify, model our process then, to synthesize the corrector or even to implement other more advanced control laws. The Arduino was programmed using the IDE software. The program allows the Arduino to perform the ambient environment regulation within the incubator through the dimmer control of the heating system.

\section{Heater and control module}

The heating system plays an important role in all closed incubators. This system compensates for any loss of 
temperature. Generally, the heating system is an electrical resistance that converts electrical energy into heat. For our experiment, the heating system of the incubator is used but with another design of its control circuit [25].

This section presents a phase control method implemented on Arduino microcontroller to control power delivered to AC loads by using TRIAC.

Varying the root means square (rms) value of voltage supply results in varying of power delivered to the AC loads [26]. Varying the rms value of supply voltage could be done by using a TRIAC [27]. TRIAC is a bidirectional silicon controlled rectifier (SCR) or thyristor. Unlike SCR, TRIAC could conduct current in both directions which make them convenient to regulate the AC voltage. Fig. 4 shows TRIAC output voltage waveform.

The main circuit could be separated to two parts, zerocrossing detector and AC load driver circuit. The zero-crossing detector [28] is the upper part with an optocoupler, bridge rectifier, and two current limiting resistors.

The load rms voltage is same as the TRIAC's output rms voltage. The TRIAC's output rms voltage is related to delay angle, $\alpha$ [29] which is represented as:

$$
\begin{gathered}
V_{L(r m s)}=V_{s} \sqrt{\frac{1}{\pi}\left[(\pi-\alpha)+\frac{\sin 2 \alpha}{2}\right]} \\
\text { Where, } \quad V_{L(r m s)}=\text { TRIAC } \\
V_{s}=\text { Supply voltage } \\
\alpha=\text { delay angle, in radian }
\end{gathered}
$$$$
\text { Where, } \quad V_{L(r m s)}=\text { TRIAC rms output voltage }
$$

According to Fig. 2, it is noted that the heater control is divided into several modules, which is presented in the following Fig. 5.

The lower part is the AC load driver constructed by the TRIAC, the MOC3021 optocoupler with the resistor $(1 \mathrm{k} \Omega)$. If the load is inductive (such as a motor) then the combined resistors-capacitors (RC) will be added to the circuit and connected in parallel to the TRIAC with a $39 \Omega$ resistor and a $0.01 \mu \mathrm{F}$ capacitor. The snubber circuit is excluded in Fig. 5 as a resistive load is used in this paper.

In the phase, control technique is implemented, and Arduino is programmed to fire the gate pulses to TRIAC for a number of microseconds. After a period of time the main supply voltage crosses zero. Therefore, a zero crossing detector (ZCD) is necessary to detect when the sinusoidal supply voltage goes through zero [29]. This could avoid the unpredictable time for TRIAC conducts or in other words, during what part of the sinusoidal wave the TRIAC is turn on and lead to the unpredictable power of loads. The pulses generated by the ZCD acts as interrupt signals to the Arduino microcontroller [30]. Arduino microcontroller is then firing a pulse to the TRIAC. By controlling the time delay between zero crossing point and firing gate pulses to TRIAC, the power delivered to the AC load is controlled smoothly and effectively.

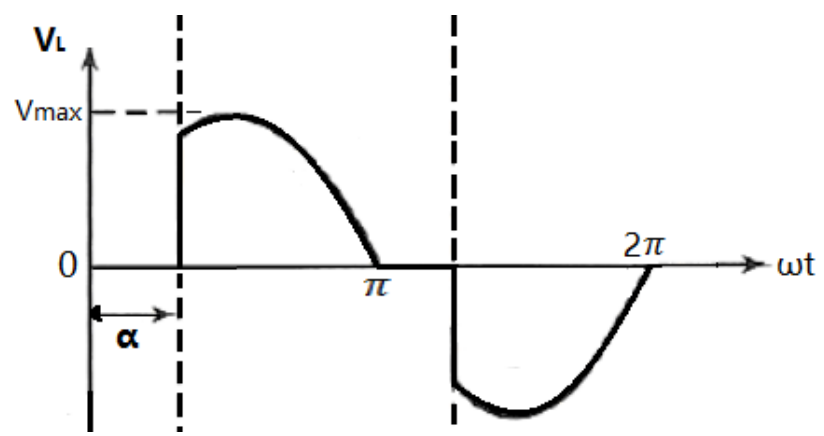

Fig. 4. TRIAC Output Voltage Waveform.

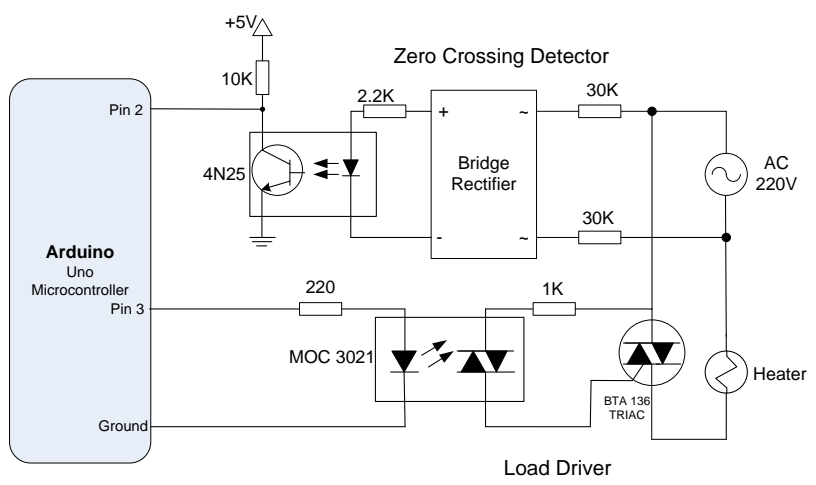

Fig. 5. Phase control technique circuit diagram.

To protect the Arduino microcontroller from being damaged by high voltage, an optocoupler MOC3021 is placed in between the microcontroller and TRIAC to isolate the high voltage side of loads and low voltage side of the Arduino microcontroller.

\section{Arduino interfaces Matlab / Simulink}

There are three ways to interface the Arduino board with Matlab/Simulink, namely:

1) Programming the Arduino Uno card as an interface card.

2) Using the ArduinoIO package.

3) Using the Arduino Target Package.

In this work, we use the first method. The solution uses the functions offered by the Arduino language which allows to send and to acquire binary data via the serial port (USB) and, on the other hand, to develop under Simulink a program to process or visualize those data.

The Arduino functions for this configuration are shown in Table 1.

TABLE. I. ARDUINO FUNCTIONS

\begin{tabular}{|l|l|}
\hline Function name & Function description \\
\hline available () & $\begin{array}{l}\text { Get the number of bits (characters) available to read } \\
\text { from the serial port. These data are stored in the } \\
\text { buffer that can back up 64 bit. }\end{array}$ \\
\hline read () & $\begin{array}{l}\text { Allows reading of incoming bits on the serial port } \\
\text { (data acquisition). }\end{array}$ \\
\hline write () & $\begin{array}{l}\text { Allows the writing of the bits on the serial port } \\
\text { (sends data) }\end{array}$ \\
\hline attachInterrupt () & An interruption to detect zero crossing \\
\hline
\end{tabular}


TABLE. II. SIMULINK BLOCKS

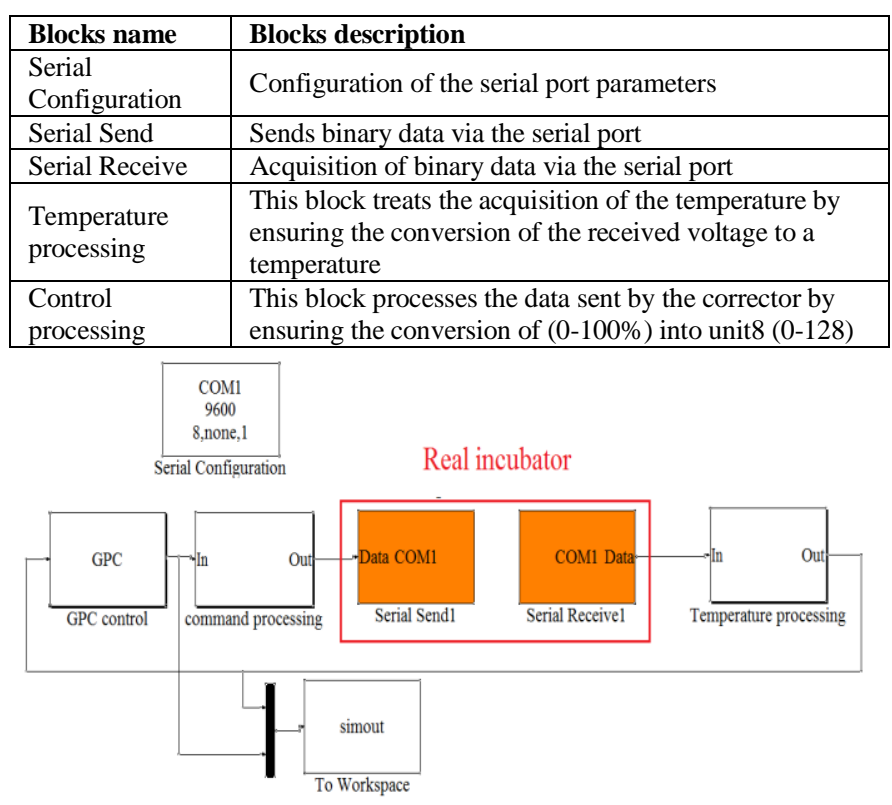

Fig. 6. Simulink model of real-time temperature control.

The Simulink blocks used to process or visualize those data are shown in Table 2.

The Arduino card handles communication with the real process and Simulink. In Simulink, we implemented the feedback loop containing the corrector and the temperature processing from the sensor. The block diagram, corresponding to the operation of the acquisition and temperature control chain, developed under Simulink is represented by Fig. 6.

\section{RESULTS}

\section{A. Heating element modelling}

The heating model of the incubator is considered as an input-output box. This model has, respectively, the electrical power of the radiator and the temperature in the heater as input-output variables. Knowing that the system can be modelled as a causal, linear and time invariant system, the model can be expressed as a transfer function given by (35).

The mathematical model was determined by applying an input of step type $U=100 \%$ to the input of the system, which presents the maximum control power provided. The functional diagram, corresponding to the operation of the acquisition chain and to the thermal treatment of the heating resistor, developed under Simulink is represented by Fig. 7.

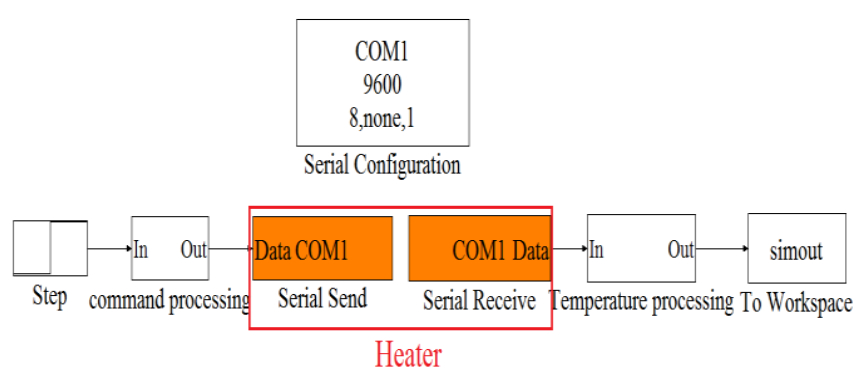

Fig. 7. Simulink blocks for the acquisition and treatment of the heater temperature.

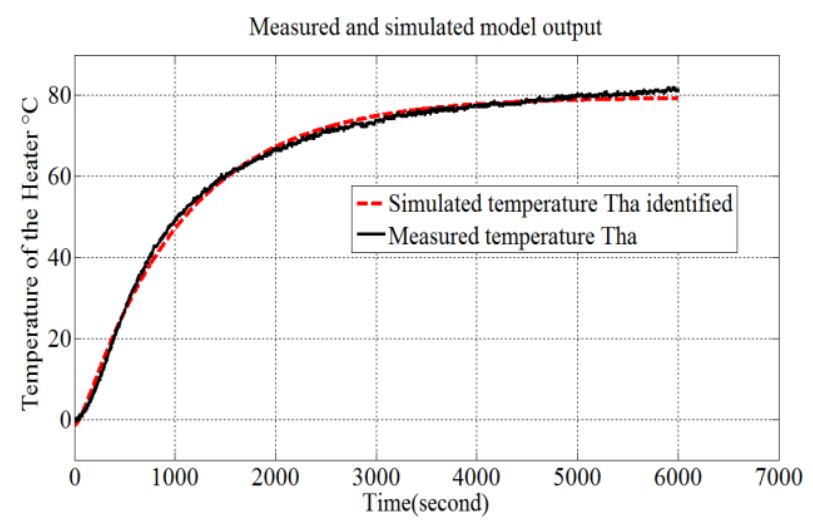

Fig. 8. Real and estimated heater temperature.

The results of this test are shown in Fig. 8. After determining the response of the system, the determination of the transfer function is made using System Identification Tool.

$$
\frac{T_{h a}}{U}(p)=\frac{0.8077}{(1127.3 p+1)}
$$

To validate the obtained model, we compare it with the actual measurement carried out as shown in Fig. 8.

\section{B. Model of the incubator subsystem with newborn}

The newborn incubator consists essentially of 6 compartments in total, as shown in Fig. 9.

A Simulink open-loop model is developed as shown in Fig. 10. This developed model includes the six compartments mentioned in the previous section (Method) with a single input power $\mathrm{U}$ and a single controlled output Ta.

Knowing that the newborn input indicates the presence of premature and $\mathrm{H} \%$ indicates the humidity in (\%), in our case, it is equal to $80 \%$. 


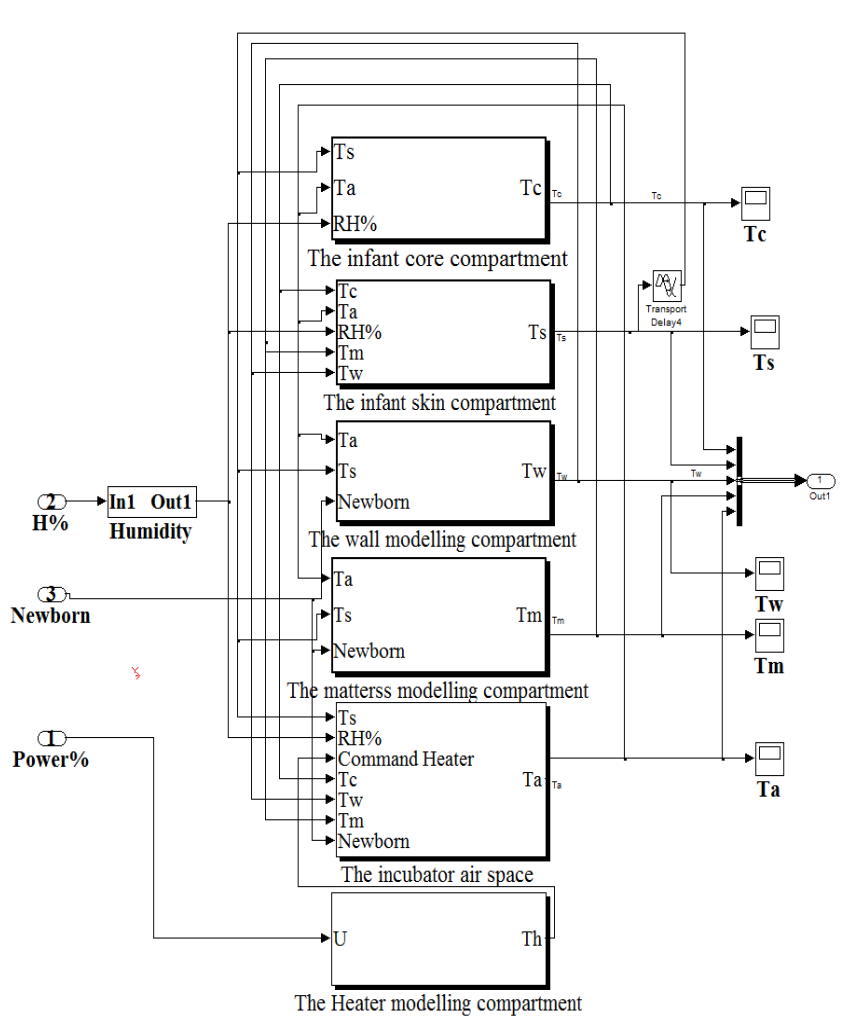

Fig. 9. Combined system compartments.

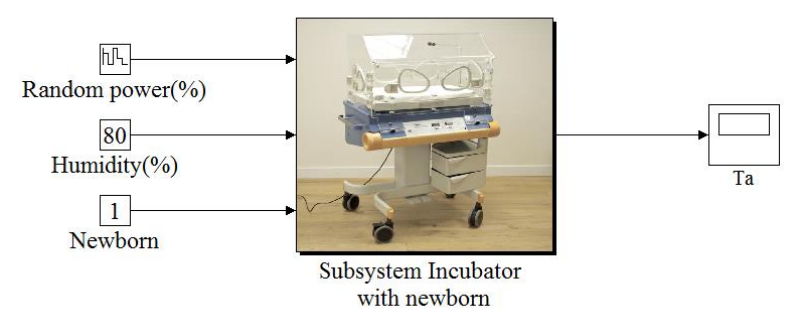

Fig. 10. Open loop infant-incubator system.

If it is assumed that in the operating region of the system is considered as linear and invariant in time, it can, therefore, be expressed as a transfer function. To linearize the Simulink model and to convert it into a transfer function, we applied a random input signal type step to the heater zones, which covers the entire range of control as shown in Fig. 11. After determining the response of the system, the determination of the transfer function is made using System Identification Tool. The process model with transfer function is:

$$
H c(p)=\frac{T_{a}}{U}(p)=K p \frac{1+T Z * p}{1+2 * Z e t a * w * p+(w * p)^{2}} e^{(-T d * p)}
$$

With: $\quad K p=0.21378, w=434.56$, Zeta $=1.5511$, $T d=30, T z=-50.432$

The results of combining the baby and incubator measured showed good agreement with the simulated model as shown in Fig. 12.

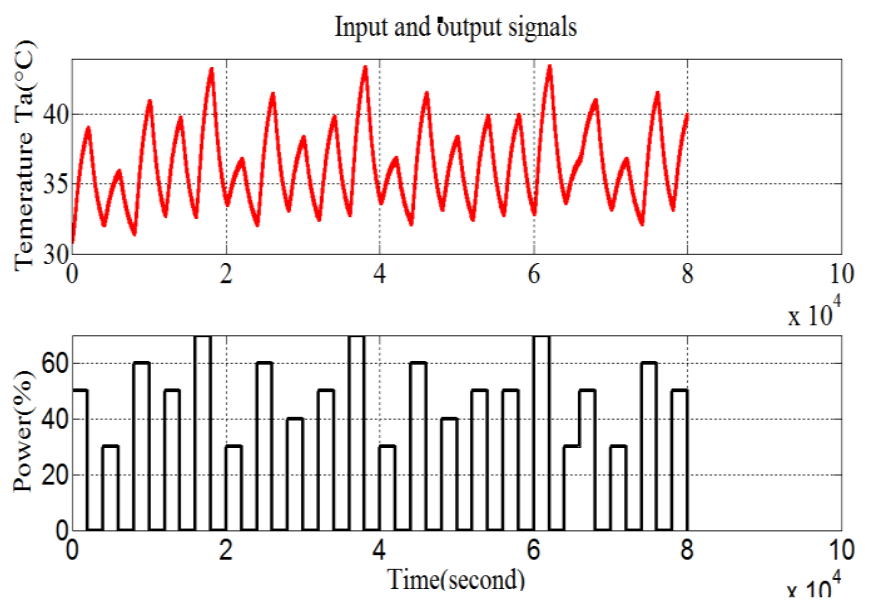

Fig. 11. Input and output signals.

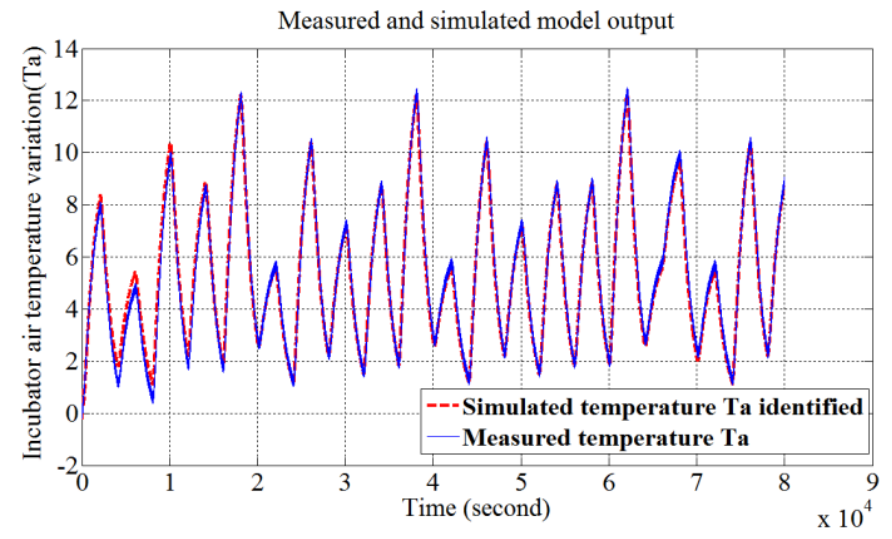

Fig. 12. Measured and estimated air temperature.

Systems controlled by digital controllers are always inherently physical systems. On the other hand, generalized predictive control is often used with a discrete prediction model used to perform predictions in a discrete manner with a sampling period $T e$. In order to establish the discretization, we exploited the $c 2 d$ function of Matlab which makes it possible to obtain the discrete equivalent of a continuous transfer function with the integration method as an argument:

$$
H d=c 2 d\left(H c, 20,{ }^{\prime} z o h^{\prime}\right)
$$

The discrete transfer function $H d$ is:

$$
H d(z)=\frac{-0.0004957 z^{2}+0.0003543 z+0.0005633}{z^{2}-1.865 z+0.867}
$$

\section{GPC and PID control with and without newborn}

Having established the model of the incubator with a newborn, we focused our efforts on the more detailed description and critical assessment of the controlled incubator system. In order to verify the improved performance of the proposed approach (GPC) compared to PID control, the main parameters are presented in Table 3.

TABLE. III. GPC AND PID PARAMETERS

\begin{tabular}{|l|l|l|l|l|l|l|}
\hline Control/Parameter & \multicolumn{1}{|c|}{$\boldsymbol{P}$} & \multicolumn{1}{c|}{$\boldsymbol{I}$} & $\boldsymbol{D}$ & \multicolumn{1}{c|}{$\boldsymbol{N}_{\mathbf{2}}$} & $\boldsymbol{N}_{\boldsymbol{u}}$ & $\boldsymbol{\lambda}$ \\
\hline GPC & - & - & - & 12 & 1 & 0.1 \\
\hline PID & 10 & 0.005 & 0 & - & - & - \\
\hline
\end{tabular}




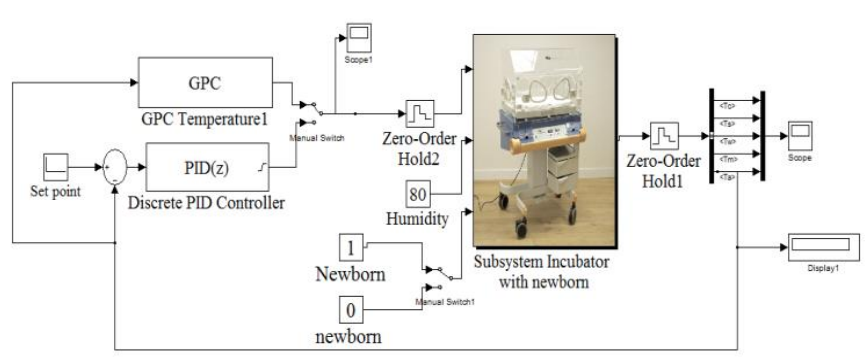

Fig. 13. Closed loop infant-incubator system.

The diagram of the simulation is shown in Fig. 13. This is a closed loop system whose elements of the direct chain are the two controllers GPC, PID and the child incubator system.

The input energy varies between $0-100 \%$ equivalent to 0 and 400 Watt. The set point is $37^{\circ} \mathrm{C}$. A manual switch is used to switch at will according to the regulation mode requested GPC or PID with or without a baby.

To find the optimal parameters of the PID controller, we tested various parameters using the Matlab/Simulink toolbox, and the best parameters were used. $K p=10, K i=0.005$, and $K d=0$, which can be deduced from the results.

For GPC, taking into account the sampling period and the time constant, the prediction horizons were set to $N_{2}=12$.

The reasonable choice of the control horizon $N_{u}$ that provides a compromise between the degree of stability and system performance must be less than $N_{2}$. In our case and based on the simulation results we have set $N_{u}=1$. In addition, the choice of the weighting factor of the control increments is based on [31] $\lambda=0.2422$.

The GPC and PID controllers have been applied and implemented to the closed incubator system with and without a newborn. The aims objective of this works is to evaluate the quality of the mode of control of the air temperature to which newborn must be raised. To validate the control system, we set the simulation time at 22 hours, whose air temperature begins at $27^{\circ} \mathrm{C}$ and the set point is set at $37^{\circ} \mathrm{C}$. Also we introduced a perturbation to the system. This perturbation is modelled as five hours opening of the incubator ports.

In the first experiment, the incubator without the baby model was used to simulate the system using PID and GPC air control. Then we keep the same parameters of each controller and we reproduce the same experiment but with an incubator occupied by a baby.

It can be deduced from the results illustrated in Fig. 14 that the GPC has a fast transient response. Also, the robustness of this strategy can be illustrated through the low overshoot and the high efficiency of fluctuation rejection. This is not the case of PID control that gave an undesirable transient response in terms of low steady state error, short rise time, short settling time and low overshoot.

When the 5 hours opening of the incubator ports was simulated, time recovery for the air temperature was 2 minutes with GPC control and 5 minutes with PID.

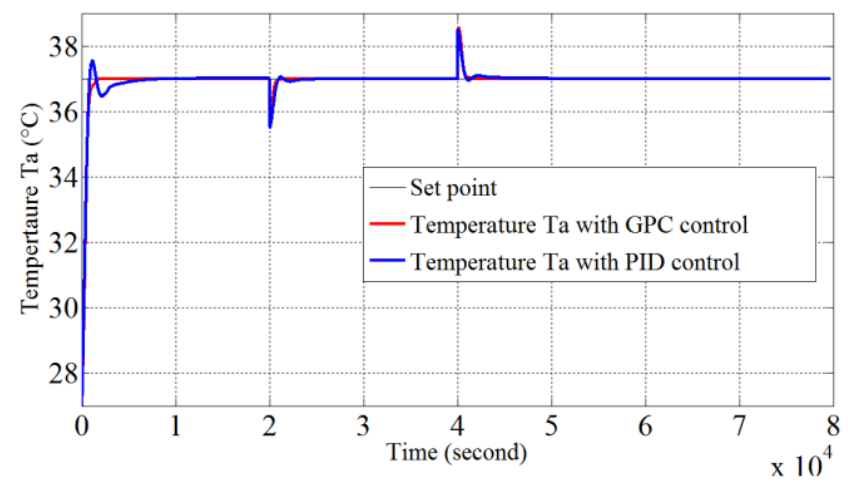

Fig. 14. Close loop step response of air temperature with GPC and PID control without premature.

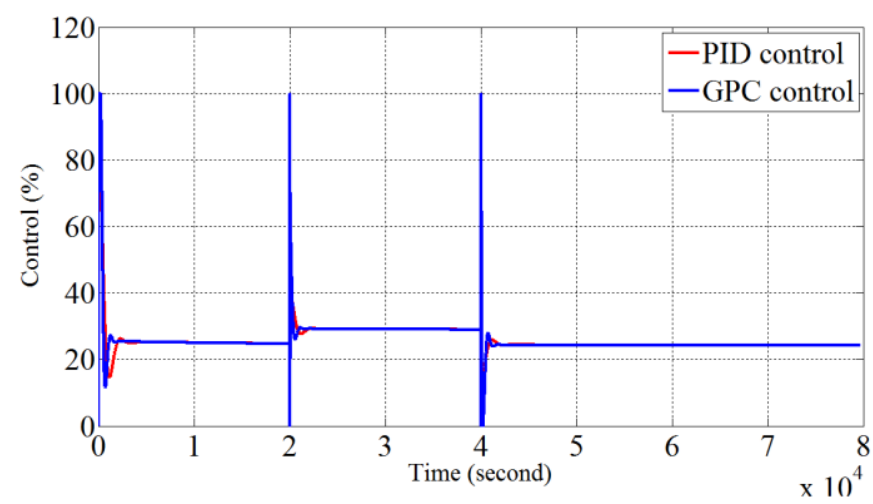

Fig. 15. Step response - Heater power closed-loop with GPC and PID control without premature.

Fig. 15 shows the evolution of the control signal of GPC and PID. These signals represent the oscillation of the heater power between 0-100 (\%).

In the case without a baby, all heat flows related to the baby in the global model are cancelled. Initial conditions related to the child correspond to those of a preterm infant with a gestation period of 28 weeks and a rectal temperature (skin) of $35.5^{\circ} \mathrm{C}$.

After determining the best parameters for each controller without baby mode, we now proceed to the global simulation of the child-incubator system and proceed to the presentation of the results. In baby mode, the manual switch is closed so that the GPC or PID controller is in the direct chain and the second manual switch that indicates the presence of the baby is closed.

In this case, all heat flows related to the baby in the global model are cancelled. Initial conditions related to the child correspond to those of a preterm infant with a gestation period of 28 weeks and a rectal temperature (skin) of $35.5^{\circ} \mathrm{C}$.

The control of the air temperature gives the result in Fig. 16. After 1100 seconds GPC respects the set point $\left(37^{\circ} \mathrm{C}\right)$ when PID respects the same set point after 5000 seconds. 


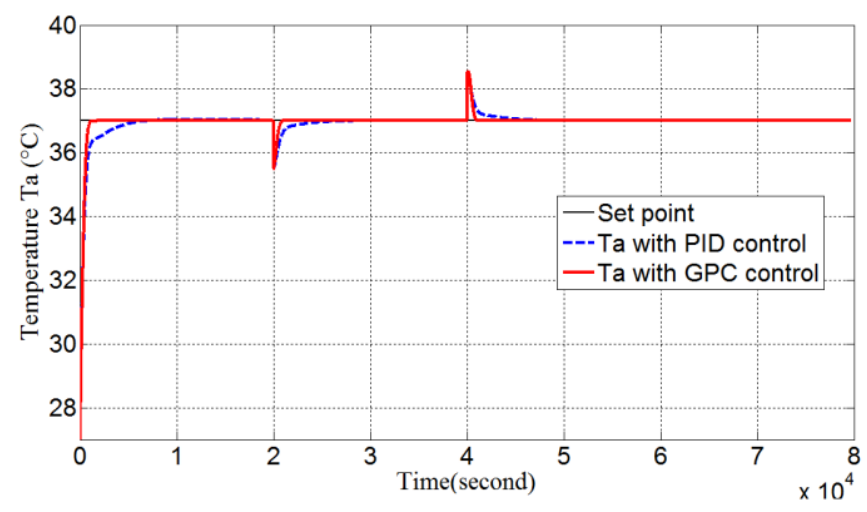

Fig. 16. Close loop step response of air temperature with GPC and PID control with premature.

The step response of the input signals of PID and GPC control that flows to the infant incubator system is demonstrated in Fig. 17. These signals represent the oscillation of the heater power between 0-100 (\%) upon the variation of the output temperature inside the incubator.

Fig. 18 shows the results of the simulation of the skin temperature and the core temperature, respectively. The initial skin and core temperature are $35^{\circ} \mathrm{C}$. It grows to achieve good stability and reaches respectively 36.5 and $37^{\circ} \mathrm{C}$ after 8 hours. The variation in core temperature of the preterm infant respectively with PID and GPC control air temperature. The core body temperature downs to around $34.7^{\circ} \mathrm{C}$, which is lower than the initial value and it increases rapidly again to $37^{\circ} \mathrm{C}$. This core body temperature is comparable with the mean of empirical clinical results reported for the preterm newborn with gestational age $29 \pm 2$ weeks and birth weight $<1000$ grams.

Similarly, with respect to the core temperature as shown in Fig. 18, the variation of the temperature of the skin of the premature infant is illustrated respectively with the regulation of the air temperature GPC and PID. The skin temperature decreases to around $34.3^{\circ} \mathrm{C}$ and rises promptly to reach $36.6^{\circ} \mathrm{C}$.

In addition, in GPC control, the rise time of the infant's core and skin temperature is more than the rise time with PID control (Fig. 18), which shows that there is a very smooth rise in core and skin temperature before it reaches the steady value. During the interval [2000s, 4000s] sampled, the hand ports incubator was opened and the internal temperature initially dropped then recovered the optimal value.

The margin of temperature between the core and the skin of newborn varies from $0.1^{\circ} \mathrm{C}$ to $0.4^{\circ} \mathrm{C}$. This is comparable with the results obtained in simulations presented in Fig. 18. In our case, the margin between the skin and core temperature is $0.3^{\circ} \mathrm{C}$. Consequently, it may be considered that the performance of the global model including the air servo control is satisfactory.

Where, $T_{r}$ is the rise time, $T_{p}$ is peak time, $T_{s t}$ is the settling time, and $M_{p}$ is the overshoot.

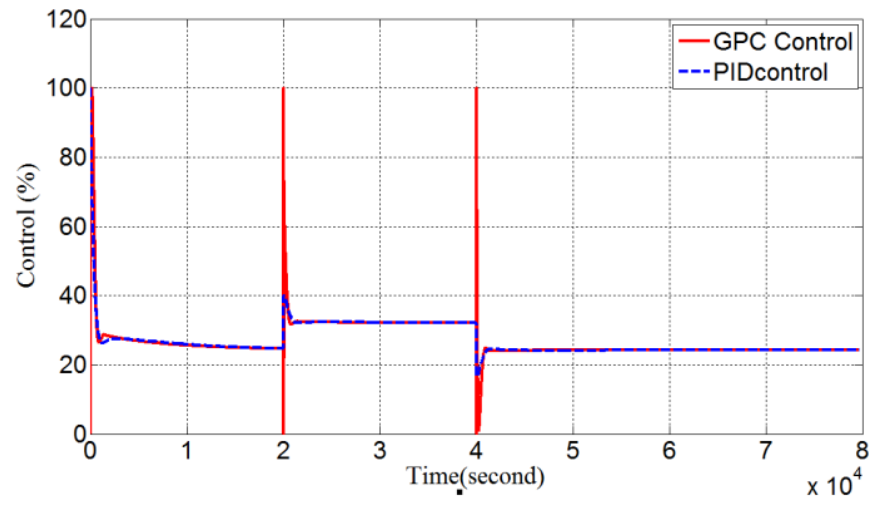

Fig. 17. Step response - Heater power closed-loop with GPC and PID control with premature.

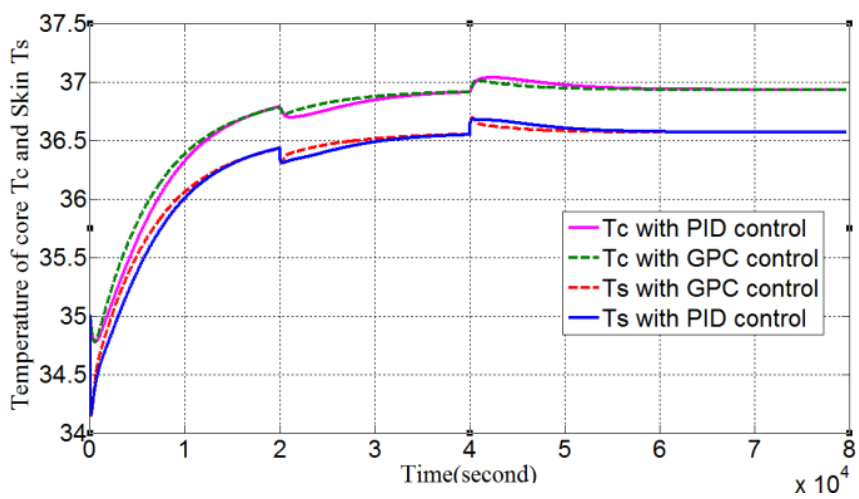

Fig. 18. Infant skin and core temperature variation with GPC and PID control.

TABLE. IV. RESULT OF TEST

\begin{tabular}{|l|l|l|l|l|}
\hline Control/Parameter & $\boldsymbol{T}_{\boldsymbol{r}}(\mathbf{s e c})$ & $\boldsymbol{T}_{\boldsymbol{p}}(\mathbf{s e c})$ & $\boldsymbol{T}_{\boldsymbol{s t}}(\mathbf{s e c})$ & $\mathbf{M}_{\mathbf{p}}(\boldsymbol{\%})$ \\
\hline GPC without premature & 760 & - & 1260 & - \\
\hline PID without premature & 720 & 1140 & 3440 & 5,6 \\
\hline GPC with premature & 660 & - & 990 & - \\
\hline PID with premature & 920 & - & 3900 & - \\
\hline
\end{tabular}

It can be deduced from Table 4 that the regulation of the neonatal incubator to the desired temperature in the shortest possible time with minimum or no overshoot, short rise time, small peak time and short settling time is provided by the GPC controller. This controller showed robustness against perturbations and parametric changes related to the prematurely associated with the system.

By comparing the results obtained by the two modes of temperature control with and without the baby, we find that the temperature control with GPC brings about better results than a PID. The GPC makes it possible to obtain a greater stability of the thermal environment thus reducing thermal stress, or decreasing the energy expenditure.

The real process of the newborn incubator with experimental set-up for the acquisition of air temperature is shown in Fig. 19. 
The responses of the experiments with the PID and the GPC controllers are presented in Fig. 20 without a newborn. The step magnitude for the air temperature was $37^{\circ} \mathrm{C}$ and it was applied with a sample time of 20 seconds, totalizing 10000 seconds of the experiment.

For the GPC controller, the step response of the incubator system presents a rapid settling time and a smaller overshoot. Unlike the PID controller, the system has shown a faster settling time, but an undesirable overshoot.

Based on the best performance of the tuning obtained by simulations result, it is important to note that the GPC controller is more efficient than PID controller.

Table 5 shows the required metabolic rates and the incubator model coefficients.

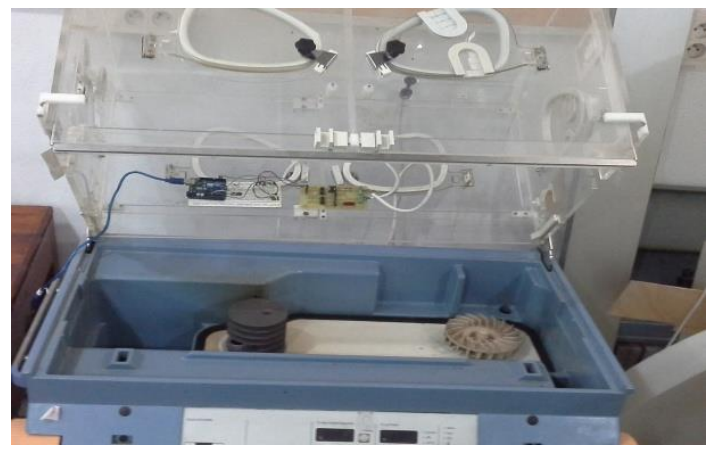

Fig. 19. Real process of neonatal incubator.

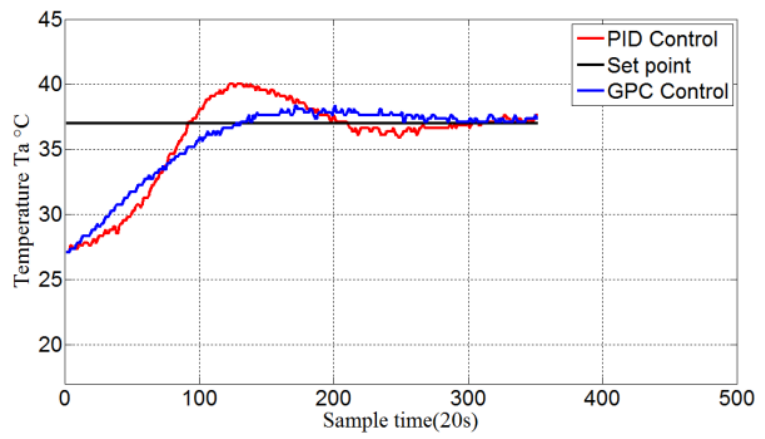

Fig. 20. Temperature responses in the experiment with the GPC and with PID methods.

\section{CONCLUSIONS}

One of the most important questions addressed by this study is "How the interference between the newborn and the incubator influences the regulation of the air temperature in the incubator?" In this direction, the combined newborn incubator model has been developed and described. This model was based on physical equations, biological data and real measurements with identification method. To answer this question, the feedback system is developed for the Simulink model using Generalized Predictive Control (GPC) and compared with PID control.

\begin{tabular}{|c|c|}
\hline \multicolumn{2}{|l|}{ Nomenclature } \\
\hline$A_{c v}$ & Surface area of skin exposed to the air, $m^{2}$ \\
\hline$A_{\text {net }}$ & Area of the mattress not covered by the infant, $m^{2}$ \\
\hline$A_{r}$ & $\begin{array}{l}\text { Surface area of the neonate's local segment normal to the } \\
\text { incubator wall, } m^{2}\end{array}$ \\
\hline$A_{s}$ & Surface area of skin in contact with the mattress, $m^{2}$ \\
\hline$A_{w i}$ & Surface area of the incubator walls, $m^{2}$ \\
\hline bf & Blood flow rate parameter, $\sec ^{-1}$ \\
\hline$C_{p a}$ & Specific heat of air, $J \cdot \mathrm{Kg}^{-1} \cdot{ }^{\circ} \mathrm{C}^{-1}$ \\
\hline$C_{p b}$ & Specific heat of the blood, $J . \mathrm{Kg}^{-1} \cdot{ }^{\circ} \mathrm{C}^{-1}$ \\
\hline$C_{p c}$ & Specific heat of the core, $J \cdot \mathrm{Kg}^{-1} \cdot{ }^{\circ} \mathrm{C}^{-1}$ \\
\hline$C_{p m}$ & Specific heat of moist air, $J . \mathrm{Kg}^{-1} \cdot{ }^{\circ} \mathrm{C}^{-1}$ \\
\hline$C_{p s}$ & Specific heat of the skin, $J \cdot \mathrm{Kg}^{-1} \cdot{ }^{\circ} \mathrm{C}^{-1}$ \\
\hline$C_{p w}^{p s}$ & Specific heat of the wall, $J \cdot \mathrm{Kg}^{-1} \cdot{ }^{\circ} \mathrm{C}^{-1}$ \\
\hline Evap & $\begin{array}{l}\text { The evaporation loss from the skin of the infant to the } \\
\text { environment, } m L / \mathrm{kg} / \text { day }\end{array}$ \\
\hline hacv & $\begin{array}{l}\text { Heat transfer coefficient for forced convection, } \\
\text { J. } \mathrm{m}^{-2} \cdot{ }^{\circ} \mathrm{C}^{-1}\end{array}$ \\
\hline hcvo & $\begin{array}{l}\text { The convective heat transfer coefficient for free } \\
\text { convection, } W \cdot m^{-2} \cdot{ }^{\circ} \mathrm{C}^{-1}\end{array}$ \\
\hline$h f g$ & Latent heat of the water, $J . \mathrm{Kg}^{-1}$ \\
\hline$h_{s c v}$ & Heat transfer coefficient for infant skin, $W \cdot m^{-2} \cdot{ }^{\circ} \mathrm{C}^{-1}$ \\
\hline IV & Inspired second volume, $m L / k g \times s e c$ \\
\hline$K_{c}$ & Thermal conductivity of the core, $W \cdot m^{-1} \cdot{ }^{\circ} C^{-1}$ \\
\hline$K_{\text {mat }}$ & Thermal conductivity of the mattress, $W \cdot m^{-1} \cdot{ }^{\circ} \mathrm{C}^{-1}$ \\
\hline$m$ & Mass of the infant, $\mathrm{Kg}$ \\
\hline$M_{a}$ & Mass of the incubator air, $\mathrm{kg}$ \\
\hline$M_{c}$ & Mass of the core, $\mathrm{kg}$ \\
\hline$M_{m}$ & Mass of the mattress, $\mathrm{kg}$ \\
\hline$M_{\text {rst }}^{m}$ & $\begin{array}{l}\text { Resting metabolic rate at the thermo neutral zone for the } \\
1^{\text {st }} \text { week of life, } W / \mathrm{m}^{2}\end{array}$ \\
\hline$M_{S}$ & Mass of the skin, $k g$ \\
\hline$M_{w}$ & Mass of the wall, $\mathrm{kg}$ \\
\hline$S_{a}$ & Surface area of the local body segment, $m^{2}$ \\
\hline$T_{x}$ & Temperature of compartment $x$ \\
\hline$t h_{m}$ & Mattress thickness, $m$ \\
\hline$V_{c b}$ & Blood volume, $m L$ \\
\hline$w_{a}$ & Humidity ratio of the inhaled air \\
\hline$w_{e x}$ & Humidity ratio of the exhaled air \\
\hline$\rho_{a}$ & Air density, $\mathrm{kg} / \mathrm{mL}$ \\
\hline$\rho_{b l}$ & Blood density, $\mathrm{kg} / \mathrm{mL}$ \\
\hline$\rho_{c}$ & Core density, $\mathrm{kg} / \mathrm{m}^{-3}$ \\
\hline$\rho_{\square 20}$ & Water density, $\mathrm{kg} / \mathrm{mL}$ \\
\hline$\sigma$ & Stefan-Boltzmann constant, $5.64 \times 10^{-8} \mathrm{~W} / \mathrm{m}^{2} . \mathrm{K}^{4}$ \\
\hline$\varepsilon_{s}$ & Radian emissivity of the skin, assumed to be 1.0 \\
\hline $\begin{array}{c}\varepsilon_{w} \\
\text { Subscripts }\end{array}$ & Radian emissivity of the wall-Plexiglass \\
\hline$c$ & Subscript for the neonate core, ${ }^{\circ} \mathrm{C}$ \\
\hline$s$ & Subscript for the neonate skin, ${ }^{\circ} \mathrm{C}$ \\
\hline$a$ & Subscript for the incubator air space, ${ }^{\circ} \mathrm{C}$ \\
\hline$w$ & Subscript for the incubator walls, ${ }^{\circ} \mathrm{C}$ \\
\hline$m$ & Subscript for the heated air entering the incubator, ${ }^{\circ} \mathrm{C}$ \\
\hline$e x$ & Subscript for the exhaled air, ${ }^{\circ} \mathrm{C}$ \\
\hline ha & Subscript for the heated air, ${ }^{\circ} \mathrm{C}$ \\
\hline
\end{tabular}

Taking into account the interactions between the model of the newborn and the model of the incubator, we have managed to control the incubator temperature with and without a newborn in the shortest feasible time with minimum overshoot, short rise time, small peak time and short settling time. These results prove that our Simulink model (incubator newborn) developed under the predictive controller GPC is satisfactory. The results that we present for the combined baby-incubator 
model were only tested with static conditions in Simulink. In addition, experiment results of PID and GPC without baby confirmed that the predictive approach is able to cope with the given control problem. As a future work, the GPC and the PID methods can be applied to a commercial incubator with a calorimetric newborn [32].

TABLE. V. Required Metabolic Rates AND the Incubator Model COEFFICIENTS

\begin{tabular}{|c|c|c|}
\hline$A_{c v}$ & $0.0765 \mathrm{~m}^{2}$ & Measured \\
\hline$A_{\text {net }}$ & $0.2019 \mathrm{~m}^{2}$ & Measured \\
\hline$A_{r}$ & $0.0427 m^{2}$ & Measured \\
\hline$A_{s}$ & $0.0085 \mathrm{~m}^{2}$ & Leblanc \\
\hline$A_{w i}$ & $1.3988 \mathrm{~m}^{2}$ & Measured \\
\hline$b f$ & $0.003531 \mathrm{l} / \mathrm{sec}$ & Derived \\
\hline$C_{p a}$ & $1007 \mathrm{~J} / \mathrm{kg} . \mathrm{C}$ & Yunus \\
\hline$C_{p b}$ & $3840 \mathrm{~J} / \mathrm{kg} . \mathrm{C}$ & Yunus \\
\hline$C_{p c}$ & $3470 \mathrm{~J} / \mathrm{kg} . \mathrm{C}$ & Yunus \\
\hline$C_{p m}$ & $1757 \mathrm{~J} / \mathrm{kg} . \mathrm{C}$ & Yunus \\
\hline$C_{p s}$ & $1900 \mathrm{~J} / \mathrm{kg} . \mathrm{C}$ & Yunus \\
\hline$C_{p w}$ & $1297 \mathrm{~J} / \mathrm{kg} . \mathrm{C}$ & Yunus \\
\hline hacv & $0.1131 \mathrm{~W} / \mathrm{m}^{2} . \mathrm{C}$ & Yunus \\
\hline$h f g$ & $2419000 \mathrm{~J} / \mathrm{kg}$ & Yunus \\
\hline$I V$ & $3.667 \mathrm{~mL} / \mathrm{kg} . \mathrm{sec}$ & Yunus \\
\hline$K_{c}$ & $0.51 \mathrm{~W} / \mathrm{m} . \mathrm{C}$ & Leblanc \\
\hline$K_{\text {mat }}$ & $0.04184 \mathrm{~W} / \mathrm{m} . \mathrm{C}$ & Al-Taweel \\
\hline$m$ & $0.900 \mathrm{~kg}$ & Leblanc \\
\hline$M_{m}$ & $0.2575 \mathrm{~kg}$ & Al-Taweel \\
\hline$M_{c}$ & $0.85 \mathrm{~kg}$ & Al-Taweel \\
\hline$M_{r s t}$ & $24.8 \mathrm{~W} / \mathrm{m}^{2}$ & Wheldon \\
\hline$M_{S}$ & $0.05 \mathrm{~kg}$ & Derived \\
\hline$M_{w}$ & $9.98 \mathrm{~kg}$ & Yunus \\
\hline$S_{a}$ & $0.085 \mathrm{~m}^{2}$ & Leblanc \\
\hline$t h_{m}$ & $0.02735 \mathrm{~m}$ & Al-Taweel \\
\hline$V_{c b}$ & $80 * m(m L)$ & Christopher \\
\hline$\rho_{a}$ & $1.145 * 10^{-6} \mathrm{~kg} / \mathrm{mL}$ & Simon \\
\hline$\rho_{b l}$ & $1.06 \mathrm{E}-3 \mathrm{~kg} / \mathrm{mL}$ & Bernd Fischer \\
\hline$\rho_{c}$ & $1080 \mathrm{~kg} / \mathrm{m}^{3}$ & Leblanc \\
\hline$\rho_{\square 2 o}$ & $0.001 \mathrm{~kg} / \mathrm{mL}$ & Simon \\
\hline$\sigma$ & $5.67 \mathrm{E}-08 \mathrm{~W} / \mathrm{m}^{2} . \mathrm{K}^{4}$ & Leblanc \\
\hline$\varepsilon_{s}$ & 0.97 & Simon \\
\hline$\varepsilon_{w}$ & 0.86 & Simon \\
\hline
\end{tabular}

REFERENCES

[1] H. Gustavo, C. Oliveira, Luis. H. Ushijima, "A Hybrid Predictive Control Scheme for Hygrothermal Process", Proceedings of the 17th World Congress, The International Federation of Automatic Control, Seoul, Korea, July 6-11, 2008.

[2] J. Medeiros, J. M. Pires, A. A. Moura, O.M. Almeida, "Certification of Neonatal Incubator Sensors through an Inferential Neural Network", Sensors, vol. 13, 2013, pp. 15613-15632.

[3] G. H. C. Oliveira, M. F. Amorim, and C. Pacholok. "A real-time predictive scheme for controlling hygrothermal conditions of neonate incubators",. In Proc. of the IFAC Symposium on Modelling and Control of Biomedical Systems, Reims/France, 2006.

[4] ML. Bernd Fischer, A. Meister, "The thermoregulation of infants: modeling and numerical simulation", BIT Numerical Mathematics, 2001; vol. 41(5), pp. 950-966.

[5] R. D. Rojas, E. L. Dove, "A mathematical model of premature baby thermo-regulation and infant incubator dynamics", International Conference on Simulation Modelling in Bioengineering, 1996, pp. 2338.

[6] J. S. Ultman, S. Berman, P. Kirlin, J. M. Vireslovic, C. B. Baer, K. H. Marks, "Electrically heated simulator for relative evaluation of alternative infant incubator environments", Med. Instrum., 1988, vol. 22(1), pp.33-8.
[7] M. H. LeBlanc, "The physics of thermal exchange between infants and their environment”, AAMI Technology Assessment Report, Feb. 1987. Vol. 21 (No.1), pp. 11-15.

[8] B. N. Simon, Jr. Narender, P. Reddy, A. Kantak, "A theoretical model of infant incubator dynamics", journal of biomechanical engineering, vol. 116, August 1994, pp. 263-269.

[9] Y. A. Al-Taweel "A simulation model of infant-incubator-feedback system with humidification and temperature control"; Thesis, The Faculty of Engineering and Science of Auckland University of Technology. August 2006.

[10] N. P. Reddy, G. Mathur, S. I. Hariharan, "Toward a fuzzy logic control of the infant incubator", Annals of Biomedical Engineering, 2009, vol. 37(10), pp. 2146-2152.

[11] M. A. Zermani, E. Feki, A. Mami, "Building simulation model of infantincubator system with decoupling predictive control", IRBM 35, 2014, pp. 189-201.

[12] P. Chessex, S. Blouet, J. Vaucher, "Environmental temperature control in very low birth weight infants (less than 1000 grams) cared for in double-walled incubators", J. Pediatr., 1988, vol. 113(2), pp.373-80.

[13] A. De Silva, M. Jayathilake, A. Galgomuwa, S. Peiris, L. Udawatta, T. Nanayakkara, "High performance temperature controller for infant incubators", International Conference on Information and Automation, New York 2006, pp. 115-120.

[14] M. A. Zermani, E. Feki, A. Mami, "Application of Adaptive Predictive Control to a Newborn Incubator", American J. of Engineering and Applied Sciences, vol. 4(2), 2011, pp. 235-243.

[15] K. A. Thomas,. R. Burr, "Preterm infant thermal care: differing thermal environments produced by air versus skin servo-control incubators", J. Perinatol, june 1999, pp. 264-270.

[16] J. A. D. Pinto, E. A. Cordova, C. B. C. Lévano, "Design and implementation of a digital PID temperature controller for neonatal incubator ESVIN", Journal of Mechanics Engineering and Automation, vol. 5, 2015, pp. 167-172.

[17] Yunus. A. Cengel, "Heat Transfer : A practical Approach", Second Edition ed: McGraw-Hill, 2002.

[18] E. F. Camacho, C. Bordons, "Model Predictive Control", Edition : Springer-Verlag, New York, 1998.

[19] D. W. Clarke, C. Mohtadi, PS. Tuffs, "Generalized predictive control: I. The basic algorithm", Part I, Automatica, vol. 23(2), 1987, pp. 137-148.

[20] M. Kubalcik, V. Bobal, "Predictive control of time-delay processes", $26^{\text {th }}$ European Conference on modelling and simulation, june 2012, Koblenz, Germany.

[21] Dräger. Incubator User Manual; Drager_Incubator_8000SC, Germany, 2017; English. Available online: http://www.frankshospitalworkshop.com/equipment/documents/infant_i ncubators/user_manuals/Drager_Incubator_8000SC_-_User_manual.pdf (accessed on 04 March 2017).

[22] E. J. L. Costa, R. C. S. Freire, J. B. A. Silva, C. M. P. Cursino, C. R. Oliveira, B. A. M. Pereira, R. F. L. Silva, "Humidity control system in newborn incubator", XIX IMEKO World Congress Fundamental and Applied Metrology, Portugal, septembre 2009, pp. 1760-1764.

[23] F. Chabni, R. Taleb, A. Benbouali, M.A. Bouthiba, "The Application of Fuzzy Control in Water Tank Level Using Arduino", IJACSA, vol. 7, No. 4, 2016, pp. 261-265.

[24] J. Oxer, H. Blemings, "Practical Arduino: Cool Projects for Open Source Hardware", Eds. Apress, 2009.

[25] L. Siang Tat, Y. Kah Haur, "Remote AC Power Control by Using Microcontroller", Journal of Telecommunication, Electronic and Computer Engineering, vol. 8, No. 12, 2016, pp. 53-58.

[26] H. Abramowitz, "Phase-Control Alternatives for Single-Phase AC Motors Offer Smart, Low-Cost, Solutions", Power Systems World, AirCare Automation, 2013.

[27] M. H. Rashid, "Power Electronics Handbook", Academic Press. 2001.

[28] A. Gupta, R. Thakur, S. Murarka, "An Efficient Approach to Zero Crossing Detection Based On Opto-Coupler", International Journal of Engineering Research and Applications, vol. 3, Issue 5, 2013, pp. 834838 . 
[29] S. Ali AL-Mawsawi, N.Allaith, H. Qassim, S. Dhiya, "An Accurate Formula for the Firing Angle of the Phase Angle Control in Terms of the Duty Cycle of The Integral Cycle Control", Journal of Automation \& Systems Engineering, 2012, pp. 30-35.

[30] Y. V. Niranjan Kumar, P. Hima Bindu, A. Divya Sneha, A. Sravani, “A Novel Implementation of Phase Control Technique for Speed Control of Induction Motor Using ARDUINO”, International Journal of Emerging
Technology and Advanced Engineering, Volume 3, Issue 4, 2013, pp. 469-473.

[31] R. B. Abdenour, P. Borne, M. Ksouri, F. Msahli, "Identification et commande numérique des procédés industriels", Paris, France: Eds. Technip; 2001.

[32] AE. Wheldon, "Energy balance in the newborn baby: use of a manikin to estimate radiant and convective heat loss", Phys Med Biol, vol. 27(2), 1982, pp. 285-96. 